\title{
The Energy Conservation and Emission Reduction Effects of Economic Agglomeration: A Spatial Perspective Based on China's Province-level Data
}

Tianyu Luo ( $\square$ hedwig1016@163.com )

Fudan University https://orcid.org/0000-0001-5536-3886

Hongmin Chen

Fudan University

\section{Research Article}

Keywords: Carbon emission intensity, Energy intensity, Economic agglomeration, Exploratory spatial data analysis, Spatial Durbin Model

Posted Date: July 12th, 2021

DOl: https://doi.org/10.21203/rs.3.rs-541875/v1

License: (c) This work is licensed under a Creative Commons Attribution 4.0 International License.

Read Full License 


\section{The Energy Conservation and Emission Reduction Effects of Economic}

2 Agglomeration: A spatial perspective based on China's province-level

3 data

4 Tianyu Luo ${ }^{1}$, Hongmin Chen²

5

\section{Abstract}

Based on the data of 30 provinces in China from 1995 to 2017, this paper combines exploratory spatial data analysis method, dynamic spatial Durbin model, and intermediary effect model to explore the spatial influence mechanism between economic agglomeration, energy intensity, and carbon emission intensity. The research results provide a basis for China's early realization of energy conservation and emission reduction goals, economical green development, and regional development strategy selection. Firstly, the results show that China's carbon emission intensity has apparent spatial agglomeration and path dependence characteristics. Secondly, the economic agglomeration has the dual effect of energy saving and emission reduction. Furthermore, there is a significant inverted N-curve relationship between economic agglomeration and carbon emission intensity and carbon emissions, and a significant U-shaped curve relationship exists between economic agglomeration and energy intensity. Finally, economic agglomeration can indirectly affect carbon emission intensity through the mediating effect of energy intensity, and there is a significant inverted U-shaped curve relationship between energy intensity and carbon emission intensity. Therefore, promoting mutual coordination of environmental policies and building a regional collaborative governance mechanism is an effective way to achieve a win-win situation for the environment and economy of Beautiful China.

Keywords Carbon emission intensity, Energy intensity, Economic agglomeration, Exploratory spatial data analysis, Spatial Durbin Model

\section{Introduction}

Against the background of global warming, countries worldwide reduce greenhouse gas emissions through global agreements, and China is facing tremendous pressure to reduce carbon dioxide emissions. In 2020, China clearly stated at the United Nations General Assembly that carbon dioxide emissions should peak before 2030 and strive to achieve carbon neutrality by 2060 . The carbon emission intensity index reflects the carbon emission efficiency in economic development, that is, the carbon dioxide emission caused by unit GDP growth. At present, the research on carbon emissions has been relatively sufficient, and the intensity of carbon emissions can better reflect the cost of carbon emissions (Shao et al., 2018; Zhou et al., 2018). Therefore, it is essential to study China's carbon emissions by paying attention to China's carbon emissions intensity. According to Figure 1, since 1995, although China's carbon emission intensity has shown a downward trend as a whole, the total emission intensity is still relatively large. Therefore, to achieve the goal of carbon neutrality, it is particularly critical to pay attention to the influencing factors of carbon emission intensity.

\footnotetext{
${ }_{1}^{1}$ Department of Environmental Science \& Engineering, Fudan University, Shanghai 200433, China hedwig1016@163.com

2 Department of Environmental Science \& Engineering, Fudan University, Shanghai 200433, China chenhongmin@fudan.edu.cn
} 


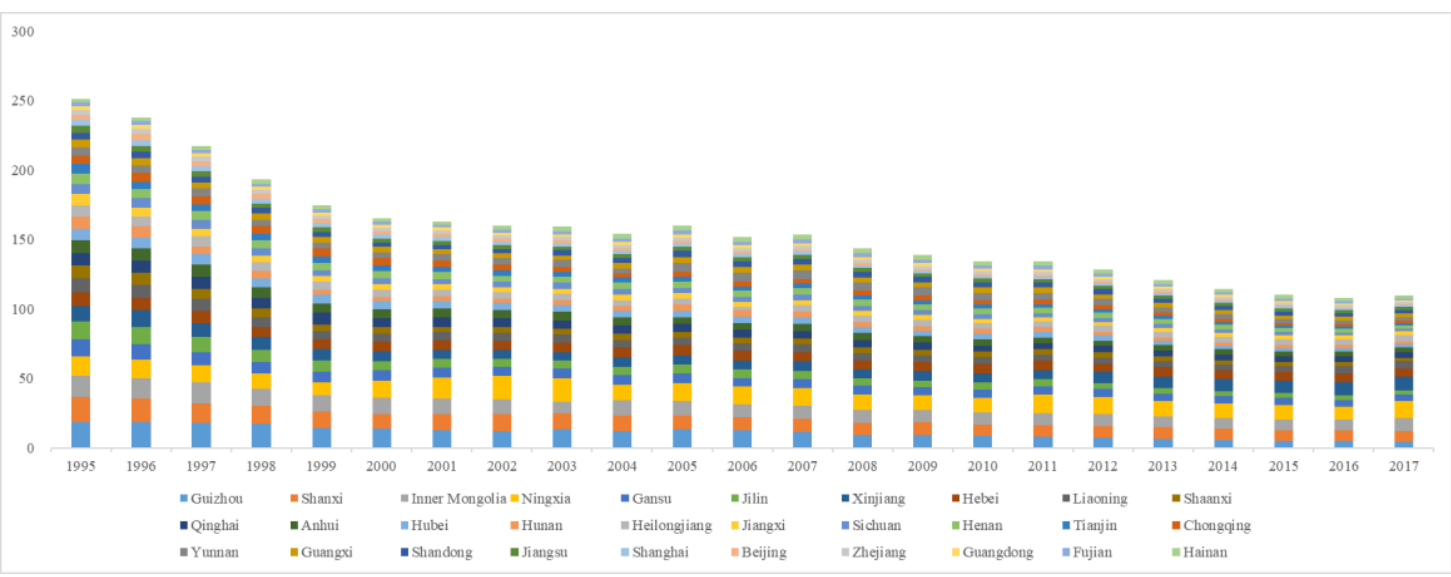

Figure 1 Carbon emission intensity in China from 1995 to 2017 (10,000 tons/100 million yuan) The main factors affecting carbon emissions include economic growth (Asumadu-Sarkodie and Owusu, 2016; Karakaya et al., 2019; Wang and Zheng, 2021), Energy Consumption (Wang and Wang, 2019; Appiah et al., 2019), urbanization (Hanif, 2018; Pata, 2018; Wang et al., 2020) and Economic Opening (Gozgor, 2017; Cetin et al., 2018; Naz et al., 2019). With China's urban economic development, regional development strategies such as the Yangtze River Economic Belt, the Silk Road Economic Belt, the 21st Century Maritime Silk Road, and the Guangdong-Hong Kong-Macao Greater Bay Area have been implemented. Economic agglomeration improves resource utilization efficiency through technology spillover effects, and at the same time, will lead to an increase in energy consumption and carbon emissions, which will have a dual impact on energy conservation and emission reduction effects. According to the theory of external economics (Marshall, 1920) and new economic geography (Fujita et al., 1999), economic agglomeration brings positive externalities to the environment through technology spillovers and economies of scale. Enterprises can share energy-saving equipment and pollution control services (Xie and Yuan, 2016) to promote resource reuse (Ehrenfeld, 2010; Zhang and Dou, 2013; Li and Zhang, 2013). On the other hand, economic agglomeration will lead to excessive concentration of production factors, cause crowding effects, and accelerate excessive consumption of resources (Frank et al., 2001; Verhoef and Nijkamp, 2002; Zeng, 2008). Furthermore, there is an uncertain or nonlinear relationship between economic agglomeration and environmental pollution (Yan et al., 2011; Liu et al., 2018; Zhang, 2018). Therefore, to promote the coordinated development of economic agglomeration and carbon emission reduction policies and achieve a win-win effect of energy conservation and emission reduction, it is particularly critical to analyze the internal impact mechanism of economic agglomeration on carbon emissions.

The burning of fossil fuels represented by coal will directly produce pollutants such as carbon dioxide and sulfur dioxide in the production and utilization process. Therefore, energy consumption is a fundamental cause of environmental pollution, such as increased carbon emissions (Akhmat et al., 2014; Rehman and Rashid, 2017, Lai et al., 2019). The improvement of energy efficiency (Li et al., 2010; Zhang et al., 2013) and energy structure (Fu et al., 2018; Yang et al., 2019) through technological innovation can effectively reduce the level of environmental pollution. The technological progress driven by economic agglomeration can significantly improve the energy utilization efficiency in the region (Shi and Shen, 2013; Liu et al., 2017; Pei et al., 2021; Sun et al., 2021). At the same time, there is a nonlinear relationship between economic agglomeration and energy consumption (Lin et al., 2011; Shi and Shen, 2012; Zhao and Lin, 2019). Therefore, this paper takes energy consumption as an intermediary variable to comprehensively and carefully consider the impact of economic, spatial agglomeration on carbon emissions. 
At present, research on carbon emissions mainly focuses on the influencing factors and control methods of total carbon emissions, and the internal relationship between carbon emissions intensity and economic agglomeration is rarely measured by including energy consumption intensity. In addition, the main research methods are decomposition analysis and standard econometric models, which can only obtain the contribution degree of influencing factors to carbon emissions but cannot explore the spatial correlation of carbon emissions and the spillover effects of influencing factors on carbon emissions. Since economic phenomena show temporal correlation and show spatial correlation to a certain extent, it is necessary and feasible to use spatial measurement methods to explore the relationship between carbon emission intensity and regional development. Therefore, focusing on China's 30 provincial-level data from 1995 to 2017, the dynamic spatial Durbin model and the intermediary effect model are used to analyze the relationship between economic agglomeration, energy intensity, and carbon emission intensity. From the perspective of spatial economic agglomeration, this article provides a necessary decision-making basis for China to effectively achieve energy conservation and emission reduction goals, economical green transformation and development, and regional development strategies.

\section{Materials and methods}

\subsection{Data source}

\subsubsection{Estimation of carbon emissions intensity}

The carbon emissions of China's provinces from 1995 to 2017 are represented by carbon emission intensity indicators. Carbon emission intensity is obtained by dividing the carbon emissions of each province's non-agricultural output (1). The calculation of carbon emission refers to the method provided by the Intergovernmental Panel on Climate Change (IPCC 2006), which is equal to the consumption of various energy sources converted to standard coal multiplied by the carbon emission coefficients. The formula is as follows:

$$
\begin{gathered}
C G=C O_{2} / G D P \\
C O_{2}=\sum_{i=1}^{14} C O_{2, i}=\sum_{i=1}^{14} E_{i} \cdot N C V_{i} \cdot C E F_{i}
\end{gathered}
$$

Where $\mathrm{CO}_{2}$ indicates carbon emission, $i$ indicates energy fuel, $E_{i}$ indicates energy consumption, $N C V_{i}$ indicates an average low calorific value of energy, $C E F_{i}$ indicates carbon emission factor of energy. The formula is as follows:

$$
C E F_{i}=C C_{i} \cdot C O F_{i} \cdot(44 / 12)
$$

Where $C C_{i}$ represents carbon content in energy, $C O F_{i}$ represents carbon oxidation factor of energy. The data comes from the "China Energy Statistical Yearbook" in 1996-2018.

\subsubsection{Estimation of economic agglomeration}

Economic agglomeration mainly refers to the density of economic activities in the unit space. The output density reflects the spatial distribution of economic activities and the carrying capacity of economic activities per unit area, which conforms to the density characteristics of economic agglomeration (Ciccone and Hall, 1993). Therefore, this paper chooses to use non-agricultural products per unit area to measure the degree of economic agglomeration.

\subsubsection{Explanatory variables}

According to the STIRPAT model and the environmental Kuznets curve hypothesis, this paper sets the control variables, which are population (POP), per capita income (LY), energy consumption structure 

specific description of each variable is shown in Table 1.

Table 1 Descriptive statistics of variables

\begin{tabular}{|c|c|c|c|c|c|c|}
\hline \multicolumn{2}{|c|}{ Variable } & Explanation & Unit & Mean & Min & Max \\
\hline $\begin{array}{l}\text { Explained } \\
\text { variable }\end{array}$ & $\begin{array}{c}\text { Carbon } \\
\text { emission } \\
\text { intensity }(\mathrm{CI})\end{array}$ & $\begin{array}{l}\text { Carbon emissions per unit of } \\
\text { non-agricultural output } \\
\text { (constant price in 1995) }\end{array}$ & $\begin{array}{l}10,000 \text { tons } / 100 \\
\text { million yuan }\end{array}$ & 5.20 & 0.61 & 18.63 \\
\hline \multirow{2}{*}{$\begin{array}{c}\text { Core } \\
\text { variable }\end{array}$} & $\begin{array}{c}\text { Economic } \\
\text { agglomeration } \\
\text { (EG) }\end{array}$ & $\begin{array}{l}\text { Output density (constant } \\
\text { price in 1995) }\end{array}$ & $\begin{array}{c}100 \text { million } \\
\text { yuan/10,000 } \\
\text { hectares }\end{array}$ & 4.59 & 0.92 & 15.55 \\
\hline & $\begin{array}{c}\text { Energy } \\
\text { intensity (EI) }\end{array}$ & $\begin{array}{l}\text { Energy consumption per unit } \\
\text { of non-agricultural output } \\
\text { (constant price in 1995) }\end{array}$ & $\begin{array}{c}10,000 \text { tons of } \\
\text { standard coal/100 } \\
\text { million yuan }\end{array}$ & 3.41 & 0.30 & 84.84 \\
\hline \multirow{6}{*}{$\begin{array}{l}\text { Control } \\
\text { variable }\end{array}$} & $\begin{array}{l}\text { Population } \\
\text { (POP) }\end{array}$ & $\begin{array}{l}\text { Population at the end of the } \\
\text { year }\end{array}$ & Million & 43.30 & 4.81 & 114.30 \\
\hline & $\begin{array}{c}\text { Per capita } \\
\text { income }(\mathrm{LY})\end{array}$ & $\begin{array}{l}\text { GDP per capita (constant } \\
\text { price in 1995) }\end{array}$ & $\begin{array}{c}\text { Million } \\
\text { yuan/person }\end{array}$ & 161.73 & 18.26 & 656.36 \\
\hline & $\begin{array}{c}\text { Energy } \\
\text { consumption } \\
\text { structure (ES) }\end{array}$ & $\begin{array}{l}\text { Proportion of coal } \\
\text { consumption in total energy } \\
\text { consumption }\end{array}$ & $\%$ & 0.66 & 0.08 & 0.93 \\
\hline & $\begin{array}{c}\text { Industrial } \\
\text { structure (IS) }\end{array}$ & $\begin{array}{l}\text { Industrial added value as a } \\
\text { proportion of GDP (constant } \\
\text { price in 1995) }\end{array}$ & $\%$ & 0.45 & 0.19 & 0.66 \\
\hline & $\begin{array}{l}\text { Technological } \\
\text { progress (RD) }\end{array}$ & $\begin{array}{l}\text { The average number of patent } \\
\text { authorizations per } 100 \mathrm{R} \& \mathrm{D} \\
\text { employees }\end{array}$ & Pieces/100 people & 153.13 & 2.42 & 2489.38 \\
\hline & $\begin{array}{c}\text { Economic } \\
\text { opening rate } \\
\text { (FDI) }\end{array}$ & $\begin{array}{l}\text { Investment amount of foreign } \\
\text { enterprises }\end{array}$ & $\begin{array}{l}100 \text { million U.S. } \\
\text { dollars }\end{array}$ & 736.42 & 1.43 & 17622.27 \\
\hline
\end{tabular}
statistical data of 30 Chinese provinces (excluding Tibet, Hong Kong, Macao, and Taiwan) from 1995

114 to 2017. The data mainly comes from the "China Statistical Yearbook," "China Compendium of

115 Statistics," "China Energy Statistical Yearbook," "China Statistical Yearbook on Science and

116 Technology," "China Statistical Yearbook on Environment," and province (autonomous region,

117 municipality) statistical yearbook. Among them, various indicators are deflated and adjusted at constant 118 prices in 1995.

\section{$119 \quad$ 2.1.4 Exploratory spatial data analysis}

120 The Moran's I index can explain the spatial correlation of the carbon emission intensity of 30 provinces 121 across the country very well, and the formula is as follows.

$$
\mathrm{I}=\frac{\sum_{i=1}^{n} \sum_{j=1}^{n} W_{i j}\left(X_{i}-\bar{X}\right)\left(X_{j}-\bar{X}\right)}{S^{2} \sum_{i=1}^{n} \sum_{j=1}^{n} W_{i j}}
$$

122 Where $S^{2}=\frac{\sum_{i=1}^{n}\left(x_{i}-\bar{x}\right)^{2}}{n}$ indicates sample variance, $\mathrm{X}_{\mathrm{i}}$ and $\mathrm{X}_{\mathrm{j}}$ respectively represent carbon intensity 
of regions $\mathrm{i}$ and $\mathrm{j}, \mathrm{n}$ is the total number of regions, $\mathrm{W}_{\mathrm{ij}}$ is the spatial weight matrix.

The spatial correlation of data is a prerequisite for building a spatial model, so the spatial correlation of core variables needs to be tested first. According to Table 2, the results show that the Moran's I index of China's carbon emission intensity in 1995-2017 is greater than 0 , the p-value is less than 0.01 , which indicates the carbon emission intensity of each province has a significant positive spatial correlation. Secondly, the Moran's I index from 1995 to 2017 generally shows an upward trend, indicating that the accumulation effect of inter-provincial carbon emission intensity tends to strengthen, and the differences among different provinces have gradually widened.

Table 2 Moran's I index

\begin{tabular}{llll}
\hline Year & Moran's I & Year & Moran's I \\
\hline 1995 & $0.227 * * *$ & 2007 & $0.235^{* * *}$ \\
1996 & $0.224 * * *$ & 2008 & $0.265^{* * *}$ \\
1997 & $0.233^{* * *}$ & 2009 & $0.248^{* * *}$ \\
1998 & $0.216^{* * *}$ & 2010 & $0.257 * * *$ \\
1999 & $0.224 * * *$ & 2011 & $0.241^{* * *}$ \\
2000 & $0.192^{* * *}$ & 2012 & $0.264 * * *$ \\
2001 & $0.215^{* * *}$ & 2013 & $0.241^{* * *}$ \\
2002 & $0.220^{* * *}$ & 2014 & $0.252^{* * *}$ \\
2003 & $0.209^{* * *}$ & 2015 & $0.253^{* * *}$ \\
2004 & $0.200^{* * *}$ & 2016 & $0.255^{* * *}$ \\
2005 & $0.230^{* * *}$ & 2017 & $0.245^{* * *}$ \\
2006 & $0.176^{* * *}$ & - & - \\
\hline
\end{tabular}

“***", "***" and "**" indicate significance at the $1 \%, 5 \%$, and $10 \%$ levels, respectively, but not significant if not marked

\subsection{Spatial panel model}

The spatial panel model can be modified by the least-squares regression model. Therefore, this paper firstly builds the OLS model, and the model is as follows.

$$
\begin{gathered}
\ln c g=\beta_{0}+\beta_{1} \ln a g+\beta_{2} \ln e i+\beta_{3} \ln \mathrm{pop}+\beta_{4} \ln \mathrm{ly}+\beta_{5} \ln \text { es }+\beta_{6} \ln \text { is }+ \\
\beta_{7} \ln \mathrm{rd}+\beta_{8} \ln \mathrm{fd}+\varepsilon
\end{gathered}
$$

Secondly, based on the OLS model, this paper constructs the spatial lag model (SLM), the spatial error model (SEM), and the spatial Durbin model (SDM). Compared with the OLS model, the SLM can better reflect the spillover effect of the carbon intensity of each province. The specific model is as follows:

$$
\begin{gathered}
\operatorname{lncg}=\beta_{0}+\rho \mathrm{W} \ln \mathrm{cg}+\beta_{1} \ln a g+\beta_{2} \ln e i+\beta_{3} \ln \mathrm{pop}+\beta_{4} \ln \operatorname{ly}+\beta_{5} \ln \text { es }+ \\
\beta_{6} \ln \text { is }+\beta_{7} \ln \mathrm{rd}+\beta_{8} \ln \mathrm{fd}+\mu+\lambda+\varepsilon
\end{gathered}
$$

The superiority of the SEM is reflected in the careful consideration of other factors affecting the carbon emission intensity of each province, and the other factors are represented as random error terms. The model is as follows:

$$
\ln c g=\beta_{0}+\beta_{1} \ln a g+\beta_{2} \ln e i+\beta_{3} \ln \text { pop }+\beta_{4} \ln \operatorname{ly}+\beta_{5} \ln \text { es }+\beta_{6} \ln \text { is }+
$$




$$
\beta_{7} \ln \mathrm{rd}+\beta_{8} \ln \mathrm{fd}+\mu+\lambda+\varepsilon, \varepsilon=\delta \mathrm{W} \varepsilon+\varphi
$$

The explained variable itself may have spatial correlation, and the explanatory variable and error term may also have spatial characteristics. The SDM can reflect the spatial correlation from different sources and be modified into SLM and SEM by setting different coefficients. Based on this, this article chooses a more general SDM for analysis, and the SDM is as follows:

$$
\begin{gathered}
\ln \mathrm{cg}=\beta_{0}+\rho \mathrm{W} \ln \mathrm{cg}+\beta_{1} \ln a g+\beta_{2} \ln e i+\beta_{3} \ln \mathrm{pop}+\beta_{4} \ln \operatorname{ly}+\beta_{5} \ln e s+ \\
\beta_{6} \ln \text { is }+\beta_{7} \ln \mathrm{rd}+\beta_{8} \ln \mathrm{fd}+\theta_{1} \ln a g+\theta_{2} \ln e i+\theta_{3} \ln \mathrm{pop}+\theta_{4} \ln \operatorname{ly}+\theta_{5} \ln e s+ \\
\theta_{6} \ln i s+\theta_{7} \ln r d+\theta_{8} \ln f d+\mu+\lambda+\varepsilon
\end{gathered}
$$

In addition, there is a path-dependent characteristic of carbon emission changes from the time dimension, that is, the time lag effect. There may also be a two-way causal relationship between carbon emissions and factors such as economic growth and technological progress, resulting in endogenous problems (Shuai et al., 2011). Therefore, the lag phase of the carbon intensity variable was introduced into the standard static SDM. The dynamic SDM is as follows.

$$
\begin{gathered}
\ln c g=\beta_{0}+\ln c g_{-1}+\rho \mathrm{W} \ln \mathrm{cg}+\beta_{1} \ln a g+\beta_{2} \ln e i+\beta_{3} \ln \text { pop }+\beta_{4} \ln \operatorname{ly}+ \\
\beta_{5} \ln e s+\beta_{6} \ln \text { is }+\beta_{7} \ln \mathrm{rd}+\beta_{8} \ln \mathrm{fd}+\theta_{1} \ln a g+\theta_{2} \ln e i+\theta_{3} \ln \text { pop }+\theta_{4} \ln \operatorname{ly}+ \\
\theta_{5} \ln e s+\theta_{6} \ln i s+\theta_{7} \ln r d+\theta_{8} \ln f d+\mu+\lambda+\varepsilon
\end{gathered}
$$

The weight matrix is divided into 3 categories, namely $0-1$ weight matrix, geographic distance weight matrix, and economic distance weight matrix. The geographical distance weight matrix is the most common, represented as the reciprocal of the geographical distance of each province, and the formula is as follows.

$$
W_{i j}=1 / d_{i j}
$$

\subsection{Intermediary effect}

The mediating effect refers to the indirect effect of explanatory variables on the explained variables through intermediate variables (Mackinnon et al., 2000), tested by the widely used stepwise method (Baron and Kenny, 1999). The testing process is based on the following two conditions: the explanatory variable significantly affects the explained variable, and subsequent variables in the causal chain will be significantly affected by the previous variable. Specifically, the explanatory variable (X) has an indirect effect on the explained variable $(\mathrm{Y})$ through the intermediate variable $(\mathrm{M})$. Thus, the conduction process is as follows.

$$
\begin{gathered}
Y=c X+e_{1} \\
M=a X+e_{2} \\
Y=c^{\prime} X+b M+e_{3}
\end{gathered}
$$

\section{Result and Discussion}

\subsection{Spatial direct effect and overflow effect}

\subsubsection{Model selection and comparison}

In order to better construct the spatial model, the Lagrange multiplier test, likelihood ratio test, and Hausman test can empirically examine the scientific nature of the spatial panel Durbin model. The 
p-value of the houseman test is close to 0 . At the same time, this article pays more attention to the changes of specific individuals within the region. Therefore, both test results and theory support the use of the fixed-effects model (Baltagi, 2008).

Lagrange multiplier test and likelihood ratio test provide guidance for the choice of spatial models (Anselin and Florax, 1995; Burridge and Fingleton, 2010). According to Table 3, the LM-Error is more significant than LM-LAG, and R-LM Error is more significant than R-LM Lag, so selecting SEM is more appropriate than the SLM. According to Table 4, LR-Lag and LR-Error are significant at 1\% level, so SDM should not be simplified into SEM and SLM. In conclusion, based on test results, SDM should be selected.

Table 3 Lagrange multiplier test

\begin{tabular}{cccc}
\hline Index & Question & Result & Conclusion \\
\hline \multirow{2}{*}{ LM-Error } & Whether there is spatial correlation & $13.302^{* * *}$ & \\
& & $(0.00)$ & Yes \\
LM-Lag & Whether there is spatial correlation & $16.301^{* * *}$ & \\
& & $(0.00)$ & Yes \\
R- LM error & Whether there is spatial correlation & $7.432^{* * * *}$ & \\
& & $(0.01)$ & Yes \\
R-LM lag & Whether there is spatial correlation & $10.431^{* * *}$ & \\
& & $(0.00)$ & Yes \\
\hline
\end{tabular}

“***”, “**” and "**” indicate significance at the $1 \%, 5 \%$, and $10 \%$ levels, respectively, but not significant if not marked; p-value in parentheses

Table 4 Likelihood ratio test

\begin{tabular}{cccc}
\hline Index & Assumption & Result & Conclusion \\
\hline \multirow{2}{*}{ LR-Lag } & SLM nested in SDM & $262.900 * * *$ & \\
& & $(0.00)$ & No \\
LR-Error & SEM nested in SDM & $258.770^{* * *}$ & \\
& & $(0.00)$ & No \\
\hline
\end{tabular}

“***", “**” and "**” indicate significance at the $1 \%, 5 \%$, and $10 \%$ levels, respectively, but not significant if not marked; $\mathrm{Chi}^{2}$ in parentheses

\subsubsection{Spatial and temporal characteristics analysis of carbon emission intensity}

ArcGIS can be used to visualize China's carbon emission intensity and economic agglomeration level in 1997-2017 (Fig. 2). In the past ten years, China's total carbon emission intensity has shown a downward trend. Divided by geographical location, carbon emission intensity decreases from west to east and from north to south. The changing trend of the level of economic agglomeration is opposite to the intensity of carbon emissions, and the degree of economic agglomeration in the eastern coastal areas has always been maintained at a relatively high level. 

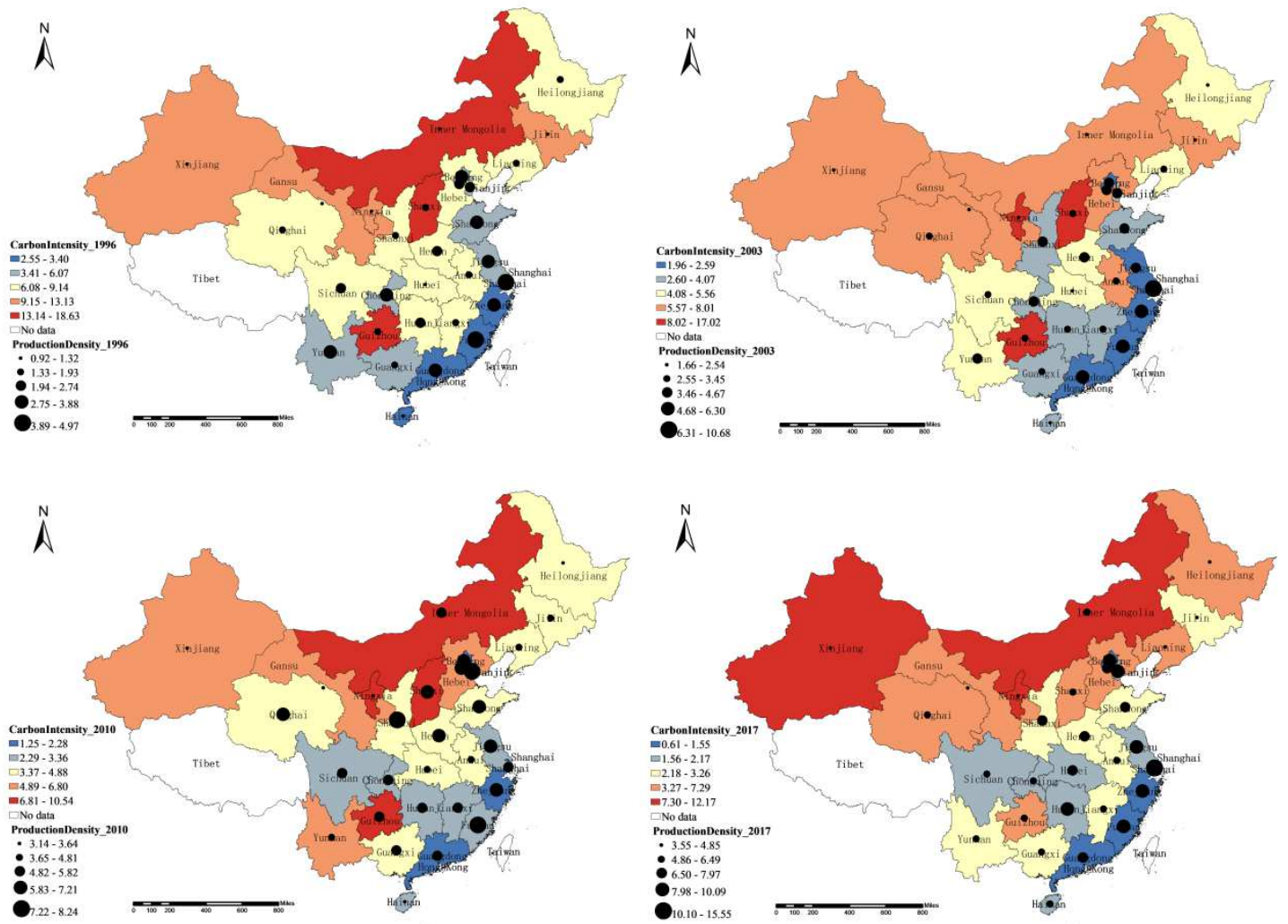

Figure 2 The spatial distribution of carbon emission intensity and economic agglomeration

\subsubsection{Spatial effects of economics agglomeration}

Due to regional differences and the estimation bias caused by time factors, this paper mainly adopts the dynamic spatial panel model with two-way fixed effects in time and space to estimate the parameters. For the convenience of comparison, the estimated results of the static SDM with fixed spatial effects, fixed time effects, and two-way fixed effects of time and space are reported in Table 5. In order to avoid the endogenous problem caused by economic agglomeration, the dynamic SDM with two-way fixed effects in time and space introduces a lagging one-phase variable of carbon emission intensity. Therefore, the results of this model are more reliable and will be discussed later.

The results show that the spatial lag coefficient of carbon emission intensity is significantly positive (Table. 5), indicating that carbon emission intensity has a strong path dependence and a "snowball" effect in the time dimension. In order to achieve the goal of carbon neutrality, China's carbon emission reduction work is both urgent and arduous. The spatial lag coefficient of economic agglomeration is significantly negative, indicating that economic agglomeration in neighboring provinces has a depressing effect on local carbon emission intensity. With the construction of urban agglomerations, the economic ties between neighboring regions have been continuously strengthened. Related industries and enterprises form a specialized division of labor within the entire urban agglomeration. When a central area appears in the urban agglomeration, the central area will continue to attract emerging industries to enter, thereby weakening the attractiveness of the surrounding areas due to the siphon effect. As a result, there is a negative correlation between the degree of economic agglomeration and the intensity of carbon dioxide emissions between regions.

The coefficients of the primary, secondary and tertiary terms of economic agglomeration have all passed the $1 \%$ significance level test, and there is a significant inverted-N relationship between economic agglomeration and carbon emission intensity. In the early stage of economic development, 
industrial gatherings had a restraining effect on carbon emission intensity. In the early days of China's reform and opening up, urbanization and industrialization were both in their infancy. When the number and scale of enterprises are limited, the scale effect promotes production efficiency, and the infrastructure can be shared. As a result, the speed of economic agglomeration greatly exceeds the intensity of carbon emissions. With the promotion of China's urbanization process, economic agglomeration plays a role in promoting carbon emission intensity. During this period, the expansion of enterprise production scale leads to an increase in the demand for production factors, so the carbon emission intensity in the production stage increases. In the period of rapid economic development in China at the beginning of the 21st century, on the one hand, the Yangtze River Delta and the Pearl River Delta have become the world's foundries. On the other hand, environmental regulatory policies, land protection policies, and the promotion of clean technologies lag behind the growth of economic agglomeration. They are leading to economic development and increasing the intensity of carbon emissions. In the end, as the strength of enterprises increases, the division of specialization is strengthened, and environmental regulations and policies are improved - the increase in the cost of environmental pollution forces enterprises to reduce carbon emissions.

Table 5 The carbon emission intensity estimation results

\begin{tabular}{|c|c|c|c|c|}
\hline \multirow{2}{*}{ Variable } & Fixed spatial & Fixed time & Two-way fixed & Dynamic SDM \\
\hline & Model 1 & Model 2 & Model 3 & Model 4 \\
\hline \multirow{2}{*}{ L.lncg } & & & & $0.210 * * *$ \\
\hline & & & & $(0.00)$ \\
\hline \multirow{2}{*}{ lneg } & -0.012 & 0.132 & -0.091 & $-0.157 * * *$ \\
\hline & $(0.82)$ & $(0.89)$ & $(-1.91)$ & $(0.00)$ \\
\hline \multirow{2}{*}{ lnseg } & -0.051 & 0.118 & 0.029 & $0.124 * * *$ \\
\hline & $(0.29)$ & $(0.21)$ & $(0.65)$ & $(0.01)$ \\
\hline \multirow{2}{*}{ lnceg } & 0.011 & 0.032 & -0.010 & $-0.034 * * *$ \\
\hline & $(0.38)$ & $(0.25)$ & $(-0.85)$ & $(0.00)$ \\
\hline \multirow{2}{*}{ lnei } & $0.803 * * *$ & $0.023 * * *$ & 0.814 & $0.686 * * *$ \\
\hline & $(0.00)$ & $(0.00)$ & $(57.92)$ & $(0.00)$ \\
\hline \multirow{2}{*}{ lnsei } & $-0.031 * * *$ & $0.007 * * *$ & -0.037 & $-0.034 * * *$ \\
\hline & $(0.00)$ & $(0.00)$ & $(-9.08)$ & $(0.00)$ \\
\hline \multirow{2}{*}{ lnly } & $-0.832 * * *$ & $0.305 * * *$ & -0.834 & $-0.702 * * *$ \\
\hline & $(0.00)$ & $(0.00)$ & $(-5.59)$ & $(0.00)$ \\
\hline \multirow{2}{*}{ Insly } & $0.024 * * *$ & $0.016 * * *$ & 0.022 & $0.018 * * *$ \\
\hline & $(0.00)$ & $(0.00)$ & (3.06) & $(0.01)$ \\
\hline \multirow{2}{*}{ lnes } & $0.271 * * *$ & $0.044 * * *$ & 0.232 & $0.174 * * *$ \\
\hline & $(0.00)$ & $(0.00)$ & (10.96) & $(0.00)$ \\
\hline \multirow{2}{*}{$\operatorname{lnis}$} & $0.167 * * *$ & $0.057 * * *$ & 0.291 & $0.261 * * *$ \\
\hline & $(0.00)$ & $(0.00)$ & (10.38) & $(0.00)$ \\
\hline \multirow{2}{*}{$\operatorname{lnrd}$} & -0.009 & $0.012 * * *$ & 0.013 & $0.015 * *$ \\
\hline & $(0.27)$ & $(0.00)$ & (1.75) & $(0.04)$ \\
\hline \multirow{2}{*}{ lnpop } & $-0.483 * * *$ & $0.018 * * *$ & -0.345 & $-0.214 * * *$ \\
\hline & $(0.00)$ & $(0.00)$ & $(-6.43)$ & $(0.00)$ \\
\hline
\end{tabular}




\begin{tabular}{|c|c|c|c|c|}
\hline \multirow{2}{*}{$\operatorname{lnfdi}$} & $0.037 * * *$ & 0.014 & 0.033 & $0.034 * * *$ \\
\hline & $(0.00)$ & $(0.25)$ & $(4.06)$ & $(0.00)$ \\
\hline \multirow{2}{*}{ Wlneg } & $-0.343 * * *$ & 0.348 & -0.436 & $-0.406^{* * *}$ \\
\hline & $(0.01)$ & $(0.39)$ & $(-3.31)$ & $(0.00)$ \\
\hline \multirow{2}{*}{ Wlnei } & 0.045 & $0.09 * * *$ & 0.404 & $0.454 * * *$ \\
\hline & $(0.4)$ & $(0.00)$ & $(6.56)$ & $(0.00)$ \\
\hline \multirow{2}{*}{ Wlnly } & $1.254 * * *$ & 0.714 & 1.241 & $0.617 * *$ \\
\hline & $(0.00)$ & $(0.21)$ & (3.83) & $(0.05)$ \\
\hline \multirow{2}{*}{ Wlnes } & $0.144 * * *$ & $0.118 * *$ & 0.020 & 0.043 \\
\hline & $(0.00)$ & $(0.04)$ & $(0.41)$ & $(0.34)$ \\
\hline \multirow{2}{*}{ Wlnis } & -0.059 & $0.131 * * *$ & 0.351 & $0.354 * * *$ \\
\hline & $(0.28)$ & $(0.00)$ & (5.15) & $(0.00)$ \\
\hline \multirow{2}{*}{ Wlnrd } & $-0.06^{* * *}$ & 0.038 & -0.010 & 0.002 \\
\hline & $(0.00)$ & $(0.37)$ & $(-0.48)$ & $(0.92)$ \\
\hline \multirow{2}{*}{ Wlnpop } & $0.808 * * *$ & 0.055 & 1.543 & $1.131 * * *$ \\
\hline & $(0.00)$ & $(0.18)$ & (11.14) & $(0.00)$ \\
\hline \multirow{2}{*}{ Wlnfdi } & $0.063 * * *$ & $0.047 * * *$ & -0.009 & -0.017 \\
\hline & $(0.00)$ & $(0.00)$ & $(-0.37)$ & $(0.45)$ \\
\hline \multirow{2}{*}{ Spatial } & $-0.139 * *$ & 0.078 & $-0.301 * * *$ & $0.441 * * *$ \\
\hline & $(0.02)$ & $(0.80)$ & $(0.00)$ & $(0.00)$ \\
\hline R-square & 0.961 & 0.769 & 0.936 & 0.943 \\
\hline
\end{tabular}

“***”, “**” and "**” indicate significance at the $1 \%, 5 \%$, and $10 \%$ levels, respectively, but not significant if not marked; p-value in parentheses

\subsubsection{Spatial effects of energy intensity}

The spatial lag coefficient of energy intensity is significantly positive at the $1 \%$ level (Table 5). On the one hand, the energy intensity of neighboring provinces positively impacts the province's carbon emission intensity. On the other hand, it also confirms the existence of regional economic competition and imitation effects. When neighboring cities develop by supporting high-pollution and high-emission industries, neighboring cities will also choose to imitate. With the development of the industrial chain of urban agglomerations, energy consumption in adjacent areas tends to be similar, and carbon emission intensity also positively correlates.

The signs of the primary and secondary coefficients of energy intensity are negative and positive, respectively, and both are significant at the 1\% level (Table 5), indicating a typical inverted U-shaped curve relationship between energy and carbon emission intensity. In the early stage of economic development, the expansion of production triggered by economic agglomeration promoted an accelerated increase in energy consumption and carbon emission intensity. However, with the implementation of energy-saving and emission reduction policies and technological progress, energy use efficiency has been improved, energy consumption structure has been optimized, and clean technology has been popularized. Ultimately, the carbon emission intensity will show a downward trend again.

\subsubsection{Effects of the control variable}

From the perspective of control variables, per capita income and its quadratic coefficient are significantly negative and significantly positive, respectively, indicating a U-shaped curve relationship 
between per capita income and carbon emission intensity. The coefficient of energy structure is significantly positive, confirming that China's production model of relying on coal resources limits the decline in carbon emission intensity. The coefficient of industrial structure is significantly positive, indicating that excessive dependence on the secondary industry is not conducive to reducing carbon emission intensity. The coefficient of technological progress is significantly positive, indicating that the improvement in production efficiency and the development of clean technology caused by technological progress has played a role in promoting energy conservation and emission reduction. The population size is significantly positive, indicating that population agglomeration will increase carbon emissions in the region. Finally, the coefficient of openness to the outside world is significantly positive, verifying the pollution refuge hypothesis, that is, China has attracted foreign investment in high-carbon emission industries.

\subsection{Energy intensity intermediary effect}

The stepwise method is a suitable method to test whether energy intensity acts as an intermediary variable for economic agglomeration and carbon emission intensity. At the same time, whether there is an energy-saving effect in economic agglomeration can also be verified.

According to Table 6, there is an inverted N-shaped relationship between economic agglomeration and carbon intensity, a U-shaped curve relationship between economic agglomeration and energy intensity, and an inverted U-shaped curve relationship between energy intensity and carbon intensity. Based on the empirical results of the intermediary effect model, it is verified that energy intensity is an intermediary variable between economic agglomeration and carbon emission intensity, and it also validates the energy-saving and emission-reduction effects of economic agglomeration. In addition, the results of models 5 and 7 also confirmed the robustness of the model 4 dynamic space Doberman model.

Table 6 Intermediary effect estimation results

\begin{tabular}{|c|c|c|c|}
\hline \multirow{2}{*}{ Variable } & EG\&CI & EG\&EI & EI\&CI \\
\hline & Model 5 & Model 6 & Model 7 \\
\hline \multirow{2}{*}{ lneg } & $-0.432 * * *$ & $-1.106^{* * *}$ & \\
\hline & $(0.00)$ & $(0.00)$ & \\
\hline \multirow{2}{*}{ lnseg } & $0.233 * * *$ & $0.343 * * *$ & \\
\hline & $(0.08)$ & $(0.00)$ & \\
\hline \multirow{2}{*}{ lnceg } & $-0.06 * * *$ & & \\
\hline & $(0.10)$ & & \\
\hline \multirow{2}{*}{ lnei } & $0.692 * * *$ & & $0.733 * * *$ \\
\hline & $(0.00)$ & & $(0.00)$ \\
\hline \multirow{2}{*}{ lnsei } & $-0.169 * * *$ & & $-0.181 * * *$ \\
\hline & $(0.00)$ & & $(0.00)$ \\
\hline \multirow{2}{*}{ lnly } & $-2.208 * * *$ & $2.864 * * *$ & $-2.334 * * *$ \\
\hline & $(0.00)$ & $(0.00)$ & $(0.00)$ \\
\hline \multirow{2}{*}{ lnsly } & $0.117 * * *$ & $-0.119 * * *$ & $0.12 * * *$ \\
\hline & $(0.00)$ & $(0.00)$ & $(0.00)$ \\
\hline \multirow{2}{*}{ lnes } & $0.219 * * *$ & $0.744 * * *$ & $0.245 * * *$ \\
\hline & $(0.00)$ & $(0.00)$ & $(0.00)$ \\
\hline $\operatorname{lnis}$ & $0.448 * * *$ & $0.196 * * *$ & $0.378 * * *$ \\
\hline
\end{tabular}




\begin{tabular}{cccc}
\hline & $(0.00)$ & $(0.29)$ & $(0.00)$ \\
\multirow{2}{*}{$\ln \mathrm{c} d$} & $0.041 * * *$ & $-0.267 * * *$ & $0.035^{* * *}$ \\
& $(0.00)$ & $(0.00)$ & $(0.00)$ \\
\multirow{2}{*}{$\operatorname{lnpop}$} & $-0.075^{* * *}$ & $0.348^{* * * *}$ & $-0.109 * * *$ \\
& $(0.00)$ & $(0.00)$ & $(0.00)$ \\
\multirow{2}{*}{$\operatorname{lnfdi}$} & $-0.14 * * *$ & $-0.306 * * *$ & $-0.128 * * *$ \\
& $(0.00)$ & $(0.00)$ & $(0.00)$ \\
constant & $14.827 * * *$ & $-11.762 * * *$ & $15.581 * * *$ \\
term & $(0.00)$ & $(0.02)$ & $(0.00)$ \\
\hline
\end{tabular}

“***”, “**” and “*” indicate significance at the $1 \%, 5 \%$, and $10 \%$ levels, respectively, but not significant if not marked; p-value in parentheses

\subsection{Spatial heterogeneity analysis}

Table 5 shows the impact of economic agglomeration in the three regions on carbon emission intensity. Due to the time lag effect of carbon emission intensity, it is more appropriate to use the dynamic spatial Doberman model. The internal economic agglomeration and carbon emission intensity of the three regions present an "inverted N" relationship, and the energy intensity and carbon emission intensity present an inverted U-shaped relationship, which is consistent with the overall national trend. In addition, economic agglomeration and energy intensity have a significant spatial spillover effect on carbon emission intensity. Therefore, the increase in the level of economic agglomeration in the region will reduce the carbon emission intensity of the surrounding areas. In contrast, the increase in the region's energy intensity will promote the increase of the carbon emission intensity of the surrounding areas.

Comparing the differences between the three regions, economic agglomeration in the western region has the most apparent inhibitory effect on carbon emission intensity, and energy intensity also has the most significant promotion effect on carbon emission intensity. Due to geographical location and historical factors, the development of western China has always lagged behind other regions. Therefore, when policies such as the development of the Chengdu-Chongqing urban agglomeration and the New Silk Road are being promoted, attention should also be paid to energy conservation and emission reduction in the western region to China's environmental improvement.

Table 7 Spatial heterogeneity estimation results

\begin{tabular}{|c|c|c|c|c|c|c|}
\hline \multirow{3}{*}{ Variable } & \multicolumn{2}{|c|}{ Eastern China } & \multicolumn{2}{|c|}{ Central China } & \multicolumn{2}{|c|}{ Western China } \\
\hline & SDM & D-SDM & SDM & D-SDM & SDM & D-SDM \\
\hline & Model 8 & Model 9 & Model 10 & Model 11 & Model 12 & Model 13 \\
\hline \multirow{2}{*}{ L.lncg } & & $0.139 * * *$ & & $0.075 * * *$ & & $0.124 * * *$ \\
\hline & & $(0.00)$ & & $(0.00)$ & & $(0.00)$ \\
\hline \multirow{2}{*}{ lneg } & $-0.268 * * *$ & $-0.283 * * *$ & $-0.437 * * *$ & $-0.536 * * *$ & $-0.786 * * *$ & $-0.972 * * *$ \\
\hline & $(0.00)$ & $(0.00)$ & $(0.00)$ & $(0.00)$ & $(0.00)$ & $(0.00)$ \\
\hline \multirow{2}{*}{ lnseg } & $0.176 * * *$ & $0.214 * * *$ & $0.164 * *$ & $0.262 * * *$ & $0.729 * * *$ & $0.885 * * *$ \\
\hline & $(0.00)$ & $(0.00)$ & $(0.03)$ & $(0.00)$ & $(0.00)$ & $(0.00)$ \\
\hline \multirow{2}{*}{ lnceg } & $-0.034 * * *$ & $-0.045 * * *$ & -0.024 & $-0.048 * *$ & $-0.208 * * *$ & $-0.246 * * *$ \\
\hline & $(0.01)$ & $(0.00)$ & $(0.20)$ & $(0.02)$ & $(0.00)$ & $(0.00)$ \\
\hline \multirow{2}{*}{ lnei } & $0.836 * * *$ & $0.743 * * *$ & $0.896 * * *$ & $0.844 * * *$ & $0.899 * * *$ & $0.850 * * *$ \\
\hline & $(0.00)$ & $(0.00)$ & $(0.00)$ & $(0.00)$ & $(0.00)$ & $(0.00)$ \\
\hline
\end{tabular}




\begin{tabular}{|c|c|c|c|c|c|c|}
\hline lnsei & $\begin{array}{c}-0.024 * \\
(0.09)\end{array}$ & $\begin{array}{l}-0.028 \\
(0.11)\end{array}$ & $\begin{array}{l}0.005 \\
(0.72)\end{array}$ & $\begin{array}{l}0.012 \\
(0.41)\end{array}$ & $\begin{array}{c}-0.048 * * * \\
(0.00)\end{array}$ & $\begin{array}{c}-0.047 * * * \\
(0.00)\end{array}$ \\
\hline lnly & $\begin{array}{c}-1.014 * * * \\
(0.00)\end{array}$ & $\begin{array}{c}-1.028 * * * \\
(0.00)\end{array}$ & $\begin{array}{c}-1.774 * * * \\
(0.00)\end{array}$ & $\begin{array}{c}-1.969 * * * \\
(0.00)\end{array}$ & $\begin{array}{c}-0.568 * * \\
(0.03)\end{array}$ & $\begin{array}{c}-0.568 * * \\
(0.02)\end{array}$ \\
\hline lnsly & $\begin{array}{c}0.036 * * * \\
(0.00)\end{array}$ & $\begin{array}{c}0.036 * * * \\
(0.00)\end{array}$ & $\begin{array}{c}0.081 * * * \\
(0.00)\end{array}$ & $\begin{array}{c}0.091 * * * \\
(0.00)\end{array}$ & $\begin{array}{l}-0.001 \\
(0.94)\end{array}$ & $\begin{array}{l}0.002 \\
(0.89)\end{array}$ \\
\hline lnes & $\begin{array}{c}0.159 * * * \\
(0.00)\end{array}$ & $\begin{array}{c}0.130 * * * \\
(0.00)\end{array}$ & $\begin{array}{c}0.324 * * * \\
(0.00)\end{array}$ & $\begin{array}{c}0.348 * * * \\
(0.00)\end{array}$ & $\begin{array}{c}0.212 * * * \\
(0.00)\end{array}$ & $\begin{array}{c}0.182 * * * \\
(0.00)\end{array}$ \\
\hline $\operatorname{lnis}$ & $\begin{array}{c}0.348 * * * \\
(0.00)\end{array}$ & $\begin{array}{c}0.316^{* * * *} \\
(0.00)\end{array}$ & $\begin{array}{c}0.463 * * * \\
(0.00)\end{array}$ & $\begin{array}{c}0.437 * * * \\
(0.00)\end{array}$ & $\begin{array}{l}0.072 \\
(0.4)\end{array}$ & $\begin{array}{l}0.076 \\
(0.38)\end{array}$ \\
\hline $\operatorname{lnrd}$ & $\begin{array}{l}-0.003 \\
(0.67)\end{array}$ & $\begin{array}{l}0.001 \\
(0.93)\end{array}$ & $\begin{array}{l}-0.004 \\
(0.71)\end{array}$ & $\begin{array}{l}0.001 \\
(0.90)\end{array}$ & $\begin{array}{l}-0.001 \\
(0.92)\end{array}$ & $\begin{array}{l}0.004 \\
(0.77)\end{array}$ \\
\hline lnpop & $\begin{array}{c}-0.181 * * \\
(0.02)\end{array}$ & $\begin{array}{l}-0.139 \\
(0.11)\end{array}$ & $\begin{array}{l}0.224 \\
(0.16)\end{array}$ & $\begin{array}{l}0.278^{*} \\
(0.08)\end{array}$ & $\begin{array}{c}-0.329 * * * \\
(0.01)\end{array}$ & $\begin{array}{c}-0.277 * * \\
(0.03)\end{array}$ \\
\hline $\operatorname{lnfdi}$ & $\begin{array}{l}0.007 \\
(0.46)\end{array}$ & $\begin{array}{l}0.009 \\
(0.35)\end{array}$ & $\begin{array}{c}-0.052 * * * \\
(0.00)\end{array}$ & $\begin{array}{c}-0.038 * * * \\
(0.01)\end{array}$ & $\begin{array}{c}0.053 * * * \\
(0.00)\end{array}$ & $\begin{array}{c}0.050 * * * \\
(0.00)\end{array}$ \\
\hline Wlneg & $\begin{array}{c}-0.644 * * * \\
(0.00)\end{array}$ & $\begin{array}{c}-0.520 * * * \\
(0.00)\end{array}$ & $\begin{array}{c}-0.562 * * * \\
(0.01)\end{array}$ & $\begin{array}{c}-0.516^{* * *} \\
(0.01)\end{array}$ & $\begin{array}{l}-0.419 \\
(0.19)\end{array}$ & $\begin{array}{c}-0.617 * \\
(0.09)\end{array}$ \\
\hline Wlnei & $\begin{array}{c}0.155^{* *} \\
(0.03)\end{array}$ & $\begin{array}{l}0.140 * \\
(0.06)\end{array}$ & $\begin{array}{c}0.209^{* *} \\
(0.03)\end{array}$ & $\begin{array}{l}0.099 \\
(0.31)\end{array}$ & $\begin{array}{c}0.366^{* * *} \\
(0.00)\end{array}$ & $\begin{array}{c}0.355^{* * * *} \\
(0.00)\end{array}$ \\
\hline Wlnly & $\begin{array}{l}0.772 \\
(0.12)\end{array}$ & $\begin{array}{l}0.580 \\
(0.29)\end{array}$ & $\begin{array}{c}-1.55^{* *} \\
(0.02)\end{array}$ & $\begin{array}{c}-1.38 * * \\
(0.04)\end{array}$ & $\begin{array}{l}-0.563 \\
(0.46)\end{array}$ & $\begin{array}{l}-0.262 \\
(0.73)\end{array}$ \\
\hline Wlnes & $\begin{array}{c}-0.061 * * \\
(0.05)\end{array}$ & $\begin{array}{l}-0.051 \\
(0.14)\end{array}$ & $\begin{array}{c}0.224 * * * \\
(0.00)\end{array}$ & $\begin{array}{c}0.22 * * * \\
(0.00)\end{array}$ & $\begin{array}{l}-0.356^{* *} \\
(0.04)\end{array}$ & $\begin{array}{c}-0.434 * * * \\
(0.01)\end{array}$ \\
\hline Wlnis & $\begin{array}{c}0.268 * * * \\
(0.00)\end{array}$ & $\begin{array}{c}0.222 * * \\
(0.02)\end{array}$ & $\begin{array}{c}0.26^{* * *} \\
(0.00)\end{array}$ & $\begin{array}{c}0.214 * * * \\
(0.00)\end{array}$ & $\begin{array}{l}0.248 \\
(0.32)\end{array}$ & $\begin{array}{l}0.199 \\
(0.43)\end{array}$ \\
\hline Wlnrd & $\begin{array}{l}-0.022 \\
(0.17)\end{array}$ & $\begin{array}{l}-0.018 \\
(0.30)\end{array}$ & $\begin{array}{c}-0.035^{*} \\
(0.10)\end{array}$ & $\begin{array}{c}-0.039 * \\
(0.09)\end{array}$ & $\begin{array}{l}0.049 \\
(0.29)\end{array}$ & $\begin{array}{l}0.068 \\
(0.13)\end{array}$ \\
\hline Wlnpop & $\begin{array}{c}0.356 * * * \\
(0.01)\end{array}$ & $\begin{array}{c}0.255^{*} \\
(0.08)\end{array}$ & $\begin{array}{l}-0.076 \\
(0.83)\end{array}$ & $\begin{array}{l}0.079 \\
(0.83)\end{array}$ & $\begin{array}{c}2.329 * * * \\
(0.00)\end{array}$ & $\begin{array}{c}2.461 * * * \\
(0.00)\end{array}$ \\
\hline Wlnfdi & $\begin{array}{c}-0.029 * * \\
(0.16)\end{array}$ & $\begin{array}{l}-0.017 \\
(0.44)\end{array}$ & $\begin{array}{l}-0.004 \\
(0.88)\end{array}$ & $\begin{array}{l}0.011 \\
(0.65)\end{array}$ & $\begin{array}{l}-0.049 \\
(0.12)\end{array}$ & $\begin{array}{l}-0.051 \\
(0.11)\end{array}$ \\
\hline Spatial & $\begin{array}{l}-0.102 \\
(0.18)\end{array}$ & $\begin{array}{l}0.105 \\
(0.19)\end{array}$ & $\begin{array}{c}-0.439 * * * \\
(0.00)\end{array}$ & $\begin{array}{c}0.359 * * * \\
(0.00)\end{array}$ & $\begin{array}{l}-0.165 \\
(0.13)\end{array}$ & $\begin{array}{c}0.229 * * \\
(0.03)\end{array}$ \\
\hline R-square & 0.902 & 0.900 & 0.934 & 0.920 & 0.784 & 0.555 \\
\hline
\end{tabular}
“***”, “**”, and “*” indicate significance at the $1 \%, 5 \%$, and $10 \%$ levels, respectively, but not significant if not marked; p-value in parentheses

\subsection{Robust test}

Finally, carbon emissions are used instead of carbon emissions intensity to test the robustness of the parameters to verify the research conclusions. According to Models 14-18 in table 8, due to the time lag effect of carbon dioxide emissions, this paper also chooses the dynamic spatial Durbin model of the two-way fixed effect of time and space to carry out the analysis. The results show that economic agglomeration and carbon dioxide emissions have an inverted $\mathrm{N}$ relationship, energy intensity and carbon dioxide emissions have an inverted $U$ relationship. That is consistent with the previous 
conclusions, indicating that the model construction is robust.

Table 8 Carbon emission estimation results

\begin{tabular}{|c|c|c|c|c|c|}
\hline \multirow{2}{*}{ Variable } & OLS & Fixed spatial & Fixed time & Two-way fixed & Dynamic SDM \\
\hline & Model 14 & Model 15 & Model 16 & Model 17 & Model 18 \\
\hline \multirow{2}{*}{ L.lncg } & & & & & $0.261 * * *$ \\
\hline & & & & & $(0.00)$ \\
\hline \multirow{2}{*}{$\operatorname{lneg}$} & $-0.326 * *$ & 0.034 & 0.096 & -0.080 & $-0.115 * *$ \\
\hline & $(0.04)$ & $(0.53)$ & $(0.50)$ & $(0.12)$ & $(0.03)$ \\
\hline \multirow{2}{*}{ lnseg } & 0.209 & -0.058 & -0.114 & 0.046 & $0.108^{* *}$ \\
\hline & $(0.15)$ & $(0.26)$ & $(0.37)$ & $(0.33)$ & $(0.02)$ \\
\hline \multirow{2}{*}{ lnceg } & $-0.066^{*}$ & 0.007 & 0.016 & -0.02 & $-0.034 * * *$ \\
\hline & $(0.09)$ & $(0.63)$ & $(0.64)$ & $(0.12)$ & $(0.01)$ \\
\hline \multirow{2}{*}{ lnei } & $0.663 * * *$ & $0.774 * * *$ & $0.639 * * *$ & $0.783 * * *$ & $0.631 * * *$ \\
\hline & $(0.00)$ & $(0.00)$ & $(0.00)$ & $(0.00)$ & $(0.00)$ \\
\hline \multirow{2}{*}{ lnsei } & $-0.158 * * *$ & $-0.024 * * *$ & $-0.159 * * *$ & $-0.028 * * *$ & $-0.023 * * *$ \\
\hline & $(0.00)$ & $(0.00)$ & $(0.00)$ & $(0.00)$ & $(0.00)$ \\
\hline \multirow{2}{*}{ lnly } & $-1.181 * * *$ & $0.331^{*}$ & $-2.399 * * *$ & $0.396^{* *}$ & $0.332 * *$ \\
\hline & $(0.00)$ & $(0.06)$ & $(0.00)$ & $(0.01)$ & $(0.03)$ \\
\hline \multirow{2}{*}{ lnsly } & $0.122 * * *$ & $0.015^{*}$ & $0.164 * * *$ & 0.01 & 0.003 \\
\hline & $(0.00)$ & $(0.08)$ & $(0.00)$ & $(0.21)$ & $(0.65)$ \\
\hline \multirow{2}{*}{ lnes } & $0.218 * * *$ & $0.238 * * *$ & $0.156^{* * *}$ & 0.198 & $0.133 * * *$ \\
\hline & $(0.00)$ & $(0.00)$ & $(0.001)$ & $(0.00)$ & $(0.00)$ \\
\hline \multirow{2}{*}{$\operatorname{lnis}$} & $0.635 * * *$ & $0.297 * * *$ & $0.766^{* * *}$ & 0.414 & $0.34 * * *$ \\
\hline & $(0.00)$ & $(0.00)$ & $(0.00)$ & $(0.00) * * *$ & $(0.00)$ \\
\hline \multirow{2}{*}{$\operatorname{lnrd}$} & $0.026^{* *}$ & $-0.015^{*}$ & $0.053 * * *$ & 0.004 & 0.007 \\
\hline & $(0.02)$ & $(0.07)$ & $(0.00)$ & $(0.58)$ & $(0.37)$ \\
\hline \multirow{2}{*}{ lnpop } & $0.904 * * *$ & $0.194 * * *$ & $0.759 * * *$ & $0.352 * * *$ & $0.323 * * *$ \\
\hline & $(0.00)$ & $(0.00)$ & $(0.00)$ & $(0.00)$ & $(0.00)$ \\
\hline \multirow{2}{*}{$\operatorname{lnfdi}$} & $-0.135 * * *$ & $0.037 * * *$ & 0.000 & $0.032 * * *$ & $0.034 * * *$ \\
\hline & $(0.00)$ & $(0.00)$ & $(0.97)$ & $(0.00)$ & $(0.00)$ \\
\hline \multirow{2}{*}{ Wlneg } & $5.092 * * *$ & $-0.462 * * *$ & -0.484 & $-0.763 * * *$ & $-0.552 * * *$ \\
\hline & $(0.00)$ & $(0.00)$ & $(0.20)$ & $(0.00)$ & $(0.00)$ \\
\hline \multirow{2}{*}{ Wlnei } & & 0.045 & $0.385 * * *$ & $0.476^{* * *}$ & $0.453 * * *$ \\
\hline & & $(0.42)$ & $(0.00)$ & $(0.00)$ & $(0.00)$ \\
\hline \multirow{2}{*}{ Wlnly } & & $2.247 * * *$ & $1.303 *$ & $2.511 * * *$ & $1.69 * * *$ \\
\hline & & $(0.00)$ & $(0.09)$ & $(0.00)$ & $(0.00)$ \\
\hline \multirow{2}{*}{ Wlnes } & & $0.089^{*}$ & -0.157 & 0.057 & $0.08 *$ \\
\hline & & $(0.07)$ & $(0.22)$ & $(0.27)$ & (0.09) \\
\hline \multirow{2}{*}{ Wlnis } & & -0.099 & $0.637 * * *$ & $0.427 * * *$ & $0.45^{* * *}$ \\
\hline & & $(0.10)$ & $(0.00)$ & $(0.00)$ & $(0.00)$ \\
\hline \multirow{2}{*}{ Wlnrd } & & -0.009 & 0.036 & 0.017 & 0.011 \\
\hline & & $(0.57)$ & $(0.39)$ & $(0.43)$ & $(0.58)$ \\
\hline Wlnpop & & $1.281 * * *$ & 0.052 & $1.953 * * *$ & $1.459 * * *$ \\
\hline
\end{tabular}




\begin{tabular}{|c|c|c|c|c|c|}
\hline & & $(0.00)$ & $(0.54)$ & $(0.00)$ & $(0.00)$ \\
\hline \multirow{2}{*}{ Wlnfdi } & & $0.046^{* *}$ & $-0.224 * * *$ & -0.03 & -0.034 \\
\hline & & $(0.03)$ & $(0.00)$ & $(0.23)$ & $(0.15)$ \\
\hline constant & $5.092 * * *$ & & & & \\
\hline term & $(0.00)$ & & & & \\
\hline \multirow{2}{*}{ Spatial } & & $-0.117 *$ & -0.044 & $-0.474 * * *$ & $0.527 * * *$ \\
\hline & & $(0.06)$ & $(0.58)$ & $(0.00)$ & $(0.00)$ \\
\hline R-square & 0.944 & 0.985 & 0.925 & 0.937 & 0.954 \\
\hline
\end{tabular}

\section{Conclusions}

With the steady progress of China's new urbanization, urban agglomeration economy, and the "two belts and one road" regional development strategies, "group-style" development and industrial agglomeration have become the driving force of China's future economic growth. However, in the face of the bright future of carbon neutrality in 2060 and the reality of high carbon emissions in various provinces, achieving win-win results with energy conservation and emission reduction has become an urgent problem to be solved. This paper uses data from 30 provinces in China from 1995 to 2017, innovatively considers the time lag and spatial spillover effects of carbon emission intensity, and introduces energy intensity as an intermediary variable. It also analyzes the internal mechanism of energy conservation and emission reduction of economic agglomeration and provides policy recommendations for China's economic green transformation development and regional development strategies.

According to the research results, in the time dimension, carbon emission intensity has path-dependent characteristics, and the "snowball" effect is prominent. In the spatial dimension, both economic agglomeration and energy intensity show spatial solid spillover effects. The carbon emission intensity of this region is highly susceptible to the influence of the economic development model and energy consumption intensity of the surrounding areas. Second, economic agglomeration can play a role in energy conservation and emission reduction through positive externalities such as technology spillovers, facility sharing, centralized supervision, and specialized division of labor. Finally, with energy intensity as an intermediary variable, there are direct and indirect effects on the mechanism of economic agglomeration on carbon emission intensity.

Based on the research conclusions, this article puts forward the following policy recommendations: First, urban agglomerations have become the main spatial form of new urbanization, and the trend of regional economic integration remains unchanged. Therefore, China should pay attention to the economic development of the central and western regions and give full play to the optimal energy conservation and emission reduction of economic agglomeration effect. Second, in policy formulation, energy conservation and emission reduction policies should be coordinated with each other, and the achievement of emission reduction targets needs to be consistent with energy conservation targets. Finally, due to the significant spatial spillover effects of economic agglomeration and energy intensity, it is necessary to reach a coordinated governance mechanism for energy conservation and emission reduction policies between regions to promote the regional linkage mechanism of China's carbon market trading. 


\section{Declarations}

349 Ethics Approval and Consent to Participate

350 Not applicable.

351 Consent to Publish

352 Not applicable.

353 Authors Contributions

354 Tianyu Luo and Hongmin Chen contributed to the study conception and design. Material preparation, 355 data collection and analysis were performed by Tianyu Luo. The first draft of the manuscript was 356 written by Tianyu Luo. Tianyu Luo and Hongmin Chen commented on previous versions of the 357 manuscript. Tianyu Luo and Hongmin Chen read and approved the final manuscript.

\section{Conflict of Interest}

359 The authors declare that they have no conflict of interest.

\section{$360 \quad$ Funding}

361 No funding was received for conducting this study.

362 All authors certify that they have no affiliations with or involvement in any organization or entity with 363 any financial interest or non-financial interest in the subject matter or materials discussed in this 364 manuscript.

365 Availability of Data and Materials

366 Some or all data, models, or code generated or used during the study are available from the 367 corresponding author by request. 


\section{References}

Akhmat G, Zaman K, Shukui T, Irfan D, Khan MM (2014) Does energy consumption contribute to environmental pollutants? Evidence from SAARC countries. Environ Sci Pollut Res 21(9):5940-5951. https://doi.org/10.1007/s11356-014-2528-1

Anselin L, Florax RJ (1995) Small sample properties of tests for spatial dependence in regression models: Some further results. In New directions in spatial econometrics. Springer, Berlin, Heidelberg, pp. $21-74$.

Appiah K, Du J, Yeboah M, Appiah R (2019) Causal correlation between energy use and carbon emissions in selected emerging economies-panel model approach. Environ Sci Pollut Res 26(8):7896-7912. https://doi.org/10.1007/s11356-019-04140-2

Asumadu-Sarkodie S, Owusu PA (2016) Carbon dioxide emissions, GDP, energy use, and population growth: a multivariate and causality analysis for Ghana, 1971-2013. Environ Sci Pollut Res 23(13):13508-13520. https://doi.org/10.1007/s11356-016-6511-x

Baltagi B (2008) Econometric analysis of panel data. John Wiley \& Sons, Hoboken.

Baron RM, Kenny DA (1986). The moderator-mediator variable distinction in social psychological research: Conceptual, strategic, and statistical considerations. J Abnorm Soc Psychol, 51(6), 1173. https://doi.org/10.1037/0022-3514.51.6.1173

Burridge P, Fingleton B (2010) Bootstrap Inference in Spatial Econometrics: the J-test. Spat Econ Anal 5(1):93-119. https://doi.org/10.1080/17421770903511346

Cetin M, Ecevit E, Yucel AG (2018) The impact of economic growth, energy consumption, trade openness, and financial development on carbon emissions: empirical evidence from Turkey. Environ Sci Pollut Res 25(36):36589-36603. https://doi.org/10.13187/es.2016.18.459

Ciccone A, Hall RE (1993) Productivity and the density of economic activity. Am Econ Rev 54-70. https://doi.org/10.3386/w4313

de Leeuw FA, Moussiopoulos N, Sahm P, Bartonova A (2001) Urban air quality in larger conurbations in the European Union. Environ Model Softw 16(4):399-414. https://doi.org/10.1016/s1364-8152(01)00007-x

Ehrenfeld J (2003) Putting a spotlight on metaphors and analogies in industrial ecology. J Ind Ecol 7(1):1-4. https://doi.org/10.1162/108819803766729131

Fu X, Michael LL, Zhang YX, Meng B (2018) Industry Structure Adjustment Based on an 

https://doi.org/10.14120/j.cnki.cn11-5057/f.2018.05.024 (in Chinese)

400

Fujita M, Krugman PR, Venables A (1999) The spatial economy: Cities, regions, and international trade. MIT press, Cambridge.

Gozgor G (2017) Does trade matter for carbon emissions in OECD countries? Evidence from a new trade openness measure. Environ Sci Pollut Res 24(36): 27813-27821. https://doi.org/10.1007/s11356-017-0361-z

Hanif I (2018) Impact of economic growth, nonrenewable and renewable energy consumption, and urbanization on carbon emissions in Sub-Saharan Africa. Environ Sci Pollut Res 25(15): 15057-15067. https://doi.org/10.1007/s11356-018-1753-4

Karakaya E, Bostan A, Özçağ M (2019) Decomposition and decoupling analysis of energy-related carbon emissions in Turkey. Environ Sci Pollut Res 26(31):32080-32091. https://doi.org/10.1007/s11356-019-06359-5

Lai X, Lu C, Liu J (2019) A synthesized factor analysis on energy consumption, economy growth, and carbon emission of construction industry in China. Environ Sci Pollut Res 26(14):13896-13905. https://doi.org/10.1007/s11356-019-04335-7

Li GZ, Jiang JR, Zhou CY (2010) Relations Between Total Factor Energy Efficiency and Environmental Pollution. China Population, Resources and Environment 20(04):50-56. https://doi.org/10.3969/j.issn.1002-2104.2010.04.009(in Chinese)

Li YG, Zhang P (2013) Have industrial agglomeration aggravated regional environmental pollution-Chinese provincial level empirical evidence. Journal of Huazhong University of Science and Technology (Social Science Edition) 27:05-97. https://doi.org/10.19648/j.cnki.jhustss1980.2013.05.017(in Chinese)

Lin HL, Li HY, Yang CH (2011) Agglomeration and productivity: Firm-level evidence from China's textile industry. China Econ Rev 22(3):313-329. https://doi.org/10.1016/j.chieco.2011.03.003 Liu XP, Sheng SH, Wang KY (2017) Whether Economic Spatial Agglomeration Can Increase Carbon Productivity or Not? Economic Review (06):107-121. https://doi.org/10.19361/j.er.2017.06.08 (in Chinese)

Liu YB, Yuan HX, Feng YD (2018) Spatial spillover and threshold effects for emissions reduction of industrial agglomeration. Journal of Applied Statistics and Management 37(02):224-234. 
https://doi.org/10.13860/j.cnki.sltj.20171131-003(in Chinese)

Mackinnon DP, Krull JL, Lockwood CM (2000) Equivalence of the Mediation, Confounding and Suppression Effect. Prev Sci 1(4):173-181. https://doi.org/10.1023/A:1026595011371

Marshall Alfred (1920) Principles of Economics. Macmillan, London.

Naz S, Sultan R, Zaman K, Aldakhil AM, Nassani AA, Abro MMQ (2019) Moderating and mediating role of renewable energy consumption, FDI inflows, and economic growth on carbon dioxide emissions: evidence from robust least square estimator. Environ Sci Pollut Res 26(3):2806-2819. https://doi.org/10.1007/s11356-018-3837-6

Pata UK (2018) The effect of urbanization and industrialization on carbon emissions in Turkey: evidence from ARDL bounds testing procedure. Environ Sci Pollut Res 25(8): 7740-7747. https://doi.org/10.1007/s11356-017-1088-6

Pei Y, Zhu Y, Wang N (2021) How do corruption and energy efficiency affect the carbon emission performance of China's industrial sectors? Environ Sci Pollut Res 1-18. https://doi.org/10.1007/s11356-021-13032-3

Rehman MU, Rashid M (2017) Energy consumption to environmental degradation, the growth appetite in SAARC nations. Renew Energ 111:284-294. https://doi.org/10.1016/j.renene.2017.03.100

Shao L, Li Y, Feng KS, Meng J, Shan YL, Guan DB (2018) Carbon emission imbalances and the structural paths of Chinese regions. Appl Energy 215:396-404. https://doi.org/10.1016/j.apenergy.2018.01.090

Shi B, Shen KR (2013) The Government Intervention, the Economic Agglomeration and the Energy Efficiency. Management World (10):6-18+187. https://doi.org/10.19744/j.cnki.11-1235/f.2013.10.002 (in Chinese)

Shi F, Shen KR (2012) Urbanization, industrial agglomeration and EBM energy efficiency. Industrial Economics Research (06):10-16+67. https://doi.org/10.13269/j.cnki.ier.2012.06.002 (in Chinese)

Sun Y, Li MX, Zhang MJ et al. (2021) A study on China's economic growth, green energy technology, and carbon emissions based on the Kuznets curve (EKC). Environ Sci Pollut Res 28(6): 7200-7211. https://doi.org/10.1007/s11356-020-11019-0

Verhoef ET, Nijkamp P (2002) Externalities in urban sustainability: environmental versus localization-type agglomeration externalities in a general spatial equilibrium model of a single-sector monocentric industrial city.

Ecol

Econom 40(2):157-179. 
https://doi.org/10.1016/S0921-8009(01)00253-1

Wang F, Fan WN, Liu J, Wang G, Chai W (2020) The effect of urbanization and spatial agglomeration on carbon emissions in urban agglomeration. Environ Sci Pollut Res 27(19), 24329-24341. https://doi.org/10.1007/s11356-020-08597-4

Wang Q, Wang SS (2019) Decoupling economic growth from carbon emissions growth in the United States: The role of research and development. J Cleaner Prod 234:702-713. https://doi.org/10.1016/j.jclepro.2019.06.174

Wang YD, Zheng YM (2021) Spatial effects of carbon emission intensity and regional development in China. Environ Sci Pollut Res 28(11), 14131-14143. https://doi.org/10.1007/s11356-020-11557-7

Xie RH, Yin YJ (2016) Research on the pollution abatement effect of industrial agglomeration's evolution. Economic Review 02:18-28. (in Chinese) https://doi.org/10.19361/j.er.2016.02.002

Yan FZ, Su L, Qiao J (2011) The exploration of the relationship between the industrial agglomeration's developments and the environmental pollution - the evidence from the manufacturing in China. Studies in Science of Science 29(01):79-83+120. https://doi.org/10.16192/j.cnki.1003-2053.2011.01.010(in Chinese)

Yang LS, Zhu JP, Jia ZJ (2019) Influencing Factors and Current Challenges of CO2Emission Reduction in China: A Perspective Based on Technological Progress. Economic Research Journal 54(11):118-132. (in Chinese)

Zeng WH (2008) Regulation on trans-boundary water pollution: a study on inter-judiciary river-basin pollution in China. China Economic Quarterly 7(2):447. (in Chinese)

Zhang K (2018) The emission reduction effects of economic agglomeration: an explanation based on spatial economics. Industrial Economics $\quad$ Research (03):64-76. https://doi.org/10.13269/j.cnki.ier.2018.03.006 (in Chinese)

Zhang K, Dou JM (2013) Research on agglomeration mechanism on pollution. Chinese Journal of Population Science (05):105-116+128. (in Chinese)

Zhang XH, Wu LQ, Zhang R, Deng SH, Zhang YZ et al. (2013) Evaluating the relationships among economic growth, energy consumption, air emissions and air environmental protection investment in China. Renew Sust Energ Rev 18:259-270. https://doi.org/10.1016/j.rser.2012.10.029

Zhao HL, Lin BQ (2019) Will agglomeration improve the energy efficiency in China's textile industry: Evidence and policy implications.

Appl 
488 https://doi.org/10.1016/j.apenergy.2018.12.068

489 Zhou ZB, Liu CJ, Zeng XM, Jiang Y, Liu WB (2018) Carbon emission performance evaluation and

490 allocation in Chinese cities. J Cleaner Prod 172:1254-1272.

491 https://doi.org/10.1016/j.jclepro.2017.10.208 